TAPROBANICA, ISSN 1800-427X. May, 2021. Vol. 10, No. 01: pp. 58-60, pl. 11.

(C) Research Center for Climate Change and Department of Biology, Faculty of Mathematics \& Natural Sciences, University of Indonesia, Depok 16424, INDONESIA.

http://www.taprobanica.org

https://doi.org/10.47605/tapro.v10i1.249

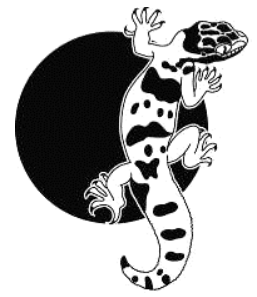

\section{First record of Gammii Frog (Nanorana gammii) from the Kingdom of Bhutan}

The amphibian fauna of the Himalayan Kingdom of Bhutan, sandwiched between India and China, is poorly known. Most data collected on this group of animals for the country comes from a few interested individuals or citizen scientists. Based on information provided by a citizen scientist (third author of this paper), we report for the first time on the occurrence of the Gammii Frog, Nanorana gammii (Anderson, 1871) in Zhemgang District of Central Bhutan. In this paper, we provide information on the newly discovered locality, habitat and conservation status of this species in Bhutan. We also report on the use of $N$. gammii by the local communities for food.

The amphibian fauna of Bhutan at present includes around 79 species (Wangyal \& Gurung 2017, Tenzin \& Wangyal 2019, Wangyal et al. 2020) out of which ten belong to the genus Nanorana Günther, 1896: $N$. annandalii (Boulenger), N. arnoldi (Dubois), N. blanfordii (Boulenger), $N$. conaensis (Fei \& Huang), $N$. ercepeae (Dubois), N. minica (Dubois), $N$. liebigii (Günther), N. parkeri (Stejneger), $N$. pleskei Günther and N. vicina (Stoliczka). However, further verification for the records of $N$. annandalii, $N$. arnoldi, $N$. conaensis and $N$. pleskei is required since they have been listed for Bhutan based on the preliminary list of herpetofauna prepared by Wangyal \& Das (2014) but without reliable voucher specimen information. It has been argued that the record of $N$. conaensis for Bhutan was likely based on a misidentification, since the type locality of this species in Tibet, China, is located approximately $1,510 \mathrm{~km}$ from the locality reported by Wangyal (2013). In summary, further field surveys and taxonomic efforts including morphological and molecular analyses are needed to clarify the status and distribution of Nanorana species in Bhutan.
Here we report on the occurrence of $N$. gammii in the Himalayan Kingdom of Bhutan, which brings the total number of Nanorana species recorded for the country to eleven. The first information on the occurrence of Nanorana species in the Zhemgang District of Central Bhutan was reported by the third author on a Facebook social media group page <Amphibians and Reptiles of Bhutan> maintained by "Amphibians and Reptiles of Bhutan - Citizens Research Initiatives"; after which a thorough search of this species was conducted in the provided location (Figs. 1, 2). Garmin eTrex GPS (WGS 84) was used to collect location data of the habitat while information on whether the species is locally consumed was collected during the survey at the site by the second and the third authors. For species identification we relied on the available guidebooks and reviews of the genus Nanorana: Frost 1985, Schleich \& Kästle 2002, Yang \& Rao 2008, Ahmed et al. 2009, Fei et al. 2010, Vasudevan \& Sondhi 2010, Subba et al. 2017, and Ohler et al. 2018. Our identification was also confirmed by Annemarie Ohler (MNHN, Paris) (pers. comm.).

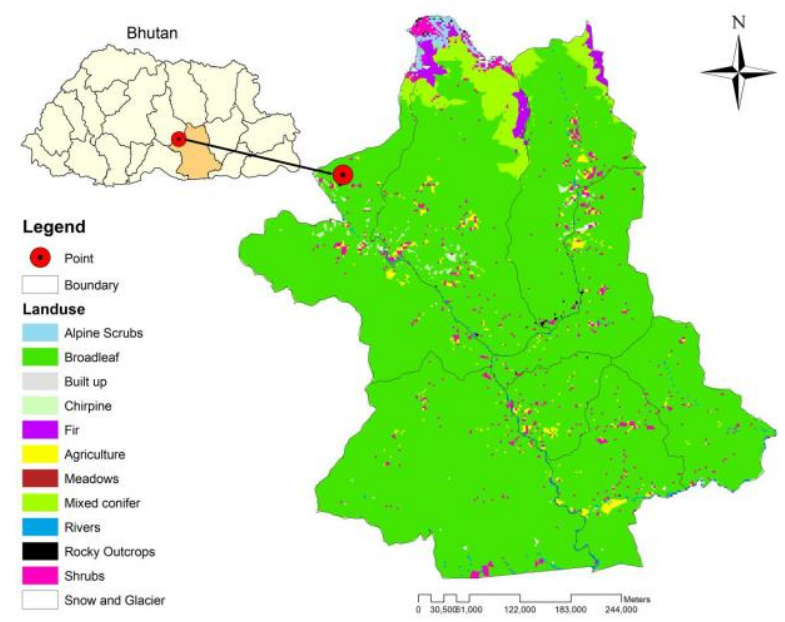

Figure 1. The locality of Nanorana gammii reported (red dot) in Zhemgang District, Central Bhutan.

A single specimen image was submitted on the Facebook social media page in September 2020 after which the area was scoured for the 
presence of other individuals by the second and third authors who did not find any more that year as they may already have hibernated. A live specimen (Fig. 3A) was collected on 1 September 2020 at 16:00 h near a home garden in suburb of Zhemgang $\left(27.215793^{\circ} \mathrm{N}\right.$, $90.658101^{\circ}$ E, alt. $1,881 \mathrm{~m}$ a.s.1.; Fig. 2). Despite our efforts to find additional specimens, none were recorded likely due to the cold weather with the approach of winter in the area. The new locality is $\sim 240 \mathrm{~km}$ air distance from the type locality of $N$. gammii in the Darjeeling Hills, West Bengal, India.

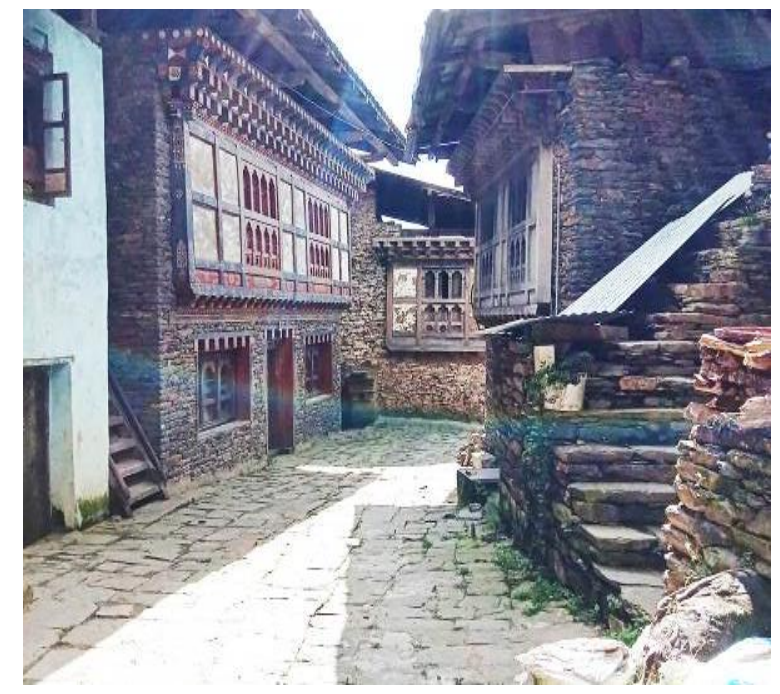

Figure 2. The exact locality where Nanorana gammii was observed, Zhemgang, Central Bhutan

Morphology. (Fig. 3A). Medium-sized frog with SVL $77.0 \mathrm{~mm}$; snout short, moderately rounded; tympanum indistinct (but can be seen on closer look), comprising half of eye diameter, distinct supratympanic fold running from the eye to the shoulder; dorsal skin smooth with a few small tubercles on the sides and a skin fold between the posterior edges of the eyelids, dorsolateral folds prominent, running from the eye to the sacrum; hind limbs of moderate length compared to other frogs of this group; finger and toe tips slightly swollen with a lateral fold along the first and fifth toes; finger length formula: $1>3>4>2$; toe length formula: $1>3>4>5>2$; toes fully webbed with the web reaching the tips of all the toes. Dorsal surface of the body olivegrey marbled with blackish-brown patches or lines; a distinct black band running from the snout through eye and further along tympanic region toward the shoulder; inter-orbital space with a black band; dorsolateral fold yellowish posteriorly; fingers and dorsal surfaces of forelimbs with black spots, hind limbs with brownish cross-bars; toes with black transverse bars and pale brown marbling.

Nanorana gammii is semi-aquatic and is mostly found in fast-flowing mountain streams (Subba et al. 2017). The locality of the specimen found is a hill station, the headquarters of Zhemgang District Administration (Fig. 3B), where the highest daily maximum temperature recorded in May 2020 was $24.5^{\circ} \mathrm{C}$ while the lowest was $9{ }^{\circ} \mathrm{C}$. The highest daily rainfall recorded at Zhemgang in May 2020 was 101.6 $\mathrm{mm}$ with a total rainfall for the month of 374.9 mm (NCHM 2021). Outside Bhutan, N. gammii is reported only from the Indian states of western Bengal specifically from the Darjeeling Hills (Ohler \& Dubious 2006), Sikkim (Subba et al. 2017) and Arunachal Pradesh (Ohler et al. 2018). Anderson described Nanorana gammii as Rana Gammii in 1871 and noted its high similarity to Rana sikimensis Jerdon, 1870 (now Ombrana sikimensis). Jerdon (1870) did not provide a detailed description of his species which was described from the same type locality in the Darjeeling Hills, West Bengal, India. Therefore, some studies considered these two taxa as synonyms (Schleich \& Kastle 2002). Ohler \& Dubois (2006) demonstrated that $N$. gammii represents a valid species, which was allocated to the subgenus Chaparana; this taxonomy was followed by subsequent authors (Frost 2007, Dinesh et al. 2009).

Nanorana gammii is not evaluated by the International Union for Conservation of Nature (IUCN) Red List due to lack of information on this poorly known species. The species does not receive any legal protection in Bhutan like any other amphibian species in the country. However, the habitats of $N$. gammii are protected well. But our preliminary queries with the local community in Zhemgang revealed that the species is common in the area and is being consumed as medicine for stomach related complications. Being used by people for its medicinal properties, proper research is necessary before allocating the species to any conservation status. Facebook or other social media groups such as Amphibians and Reptiles of Bhutan play an important role as sources of the data for new herpetofaunal records in the Kingdom of Bhutan as well as globally. Our work further supports the importance of citizen science in research for assessing amphibian distribution and diversity in Bhutan and around the world (Cosquer et al. 2012, Theobald et al. 2015). We call for further field survey efforts 


\section{Plate 11}
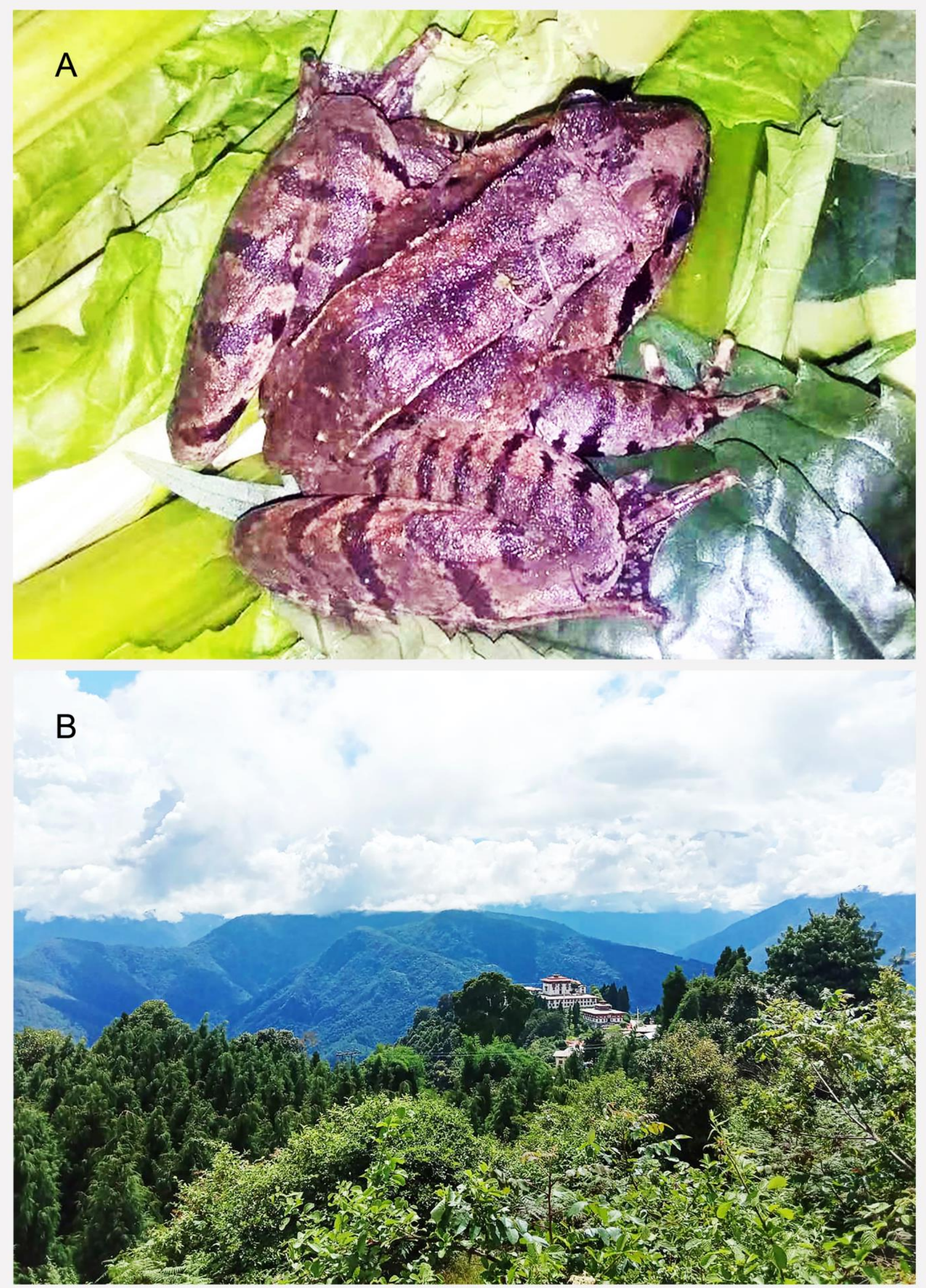

Figure 3. Nanorana gammii: (A) a live individual, (C) Photo: Kelzang Wangchuk and (B) the habitat in the hill stations of Zhemgang, Central Bhutan. 
along with collaboration between researchers and citizen scientists, which is required for further progress in our knowledge on amphibians in Bhutan.

\section{Literature cited}

Ahmed, M.F., A. Das, and S.K. Dutta (2009). Amphibians and Reptiles of Northeast India: A Photographic Guide, Aaranyak, Society for Biodiversity Conservation. Assam: 168pp.

Anderson, J. (1871). A list of the reptilian accession to the Indian Museum, Calcutta from 1865 to 1870 , with a description of some new species. Journal of the Asiatic Society of Bengal, 40: 12-39.

Cosquer, A., R. Raymond, and A.C. PrevotJulliard (2012). Observations of everyday biodiversity: a new perspective for conservation. Ecology \& Society, 17 (4): 2.

Dinesh, K.P., C. Radhakrishnan, K.V. Gururaja, and G. Bhatta (2009). An annotated checklist of Amphibia of India with some insights into the patterns of species discoveries, distribution and endemism," Records of the Zoological Survey of India (Occas. Pap.), 302: 1-153.

Fei, L., C. Ye, and J. Jiang (2010). Coloured Atlas of Chinese Amphibians. Sichuan Publishing House of Science and Technology, China.

Frost, D.R. (1985). Amphibian Species of the World. A taxonomic and Geographic Reference. Allen press, Lawrence: 732pp.

Frost, D.R. (2020). Amphibian Species of the World: An Online Reference. Version 6.1. <www.amphibiansoftheworld.amnh.org/>. Accessed on 13 September 2020.

Jerdon, T.C. (1870). Notes on Indian herpetology. Proceedings of the Asiatic Society of Bengal, 1870: 66-85.

NCHM (2020). National Center for Hydrology and Meteorology, Royal Government of Bhutan <www.nchm.gov.bt>. Accessed on 26 December 2020.

Ohler, A. and A. Dubois (2006). Phylogenetic relationships and generic taxonomy of the tribe Paini (Amphibia, Anura, Ranidae, Dicroglossinae) with diagnoses of two new genera. Zoosystema, 28: 769-784.

Ohler A., M.M. Borah, M.K. Das, C. Tesia, and S. Bordoloi (2018). A study on amphibian fauna of Arunachal Pradesh (India). Alyte, 36 (1-4): 276-288.

Schleich, H.H. and W. Kästle (eds) (2002). Amphibians and Reptiles of Nepal. Biology, Systematics, Field Guide. A. R. G. Gantner Verlag, Ruggell, Germany: 1211pp.

Subba, B., N.A. Aravind, and R. Gudasalamani (2017). Amphibians of the Sikkim Himalaya,
India: an annotated checklist. Check List, 13 (1): 2033.

Tenzin, J. and J.T. Wangyal (2019). New record of blue-eyed eastern spadefoot toad Leptobrachium вотри (Amphibia: Megophryidae) from Sarpang District in Bhutan. Journal of Threatened Taxa, 11 (3), 13385-13389.

Theobald, E.J., A.K. Ettinger, H.K. Burgess, L.B. De Bey, N.R. Schmidt et al. (2015). Global change and local solutions: tapping the unrealized potential of citizen science for biodiversity research. Biological Conservation, 181, 236-244.

Vasudevan, K. and S. Sondhi (2010). Amphibians and Reptiles of Uttarakhand, India. Wildlife Institute of India, Dehradun: 94pp.

Wangyal, J.T. (2013). New records of reptiles and amphibians from Bhutan. Journal of Threatened Taxa, 5: 4774-4783.

Wangyal, J.T. and I. Das (2014). Status, distribution and conservation issues of the amphibians of the Himalayan country of Bhutan. In: Heatwole, H. and I. Das (eds.), Conservation Biology of Amphibians of Asia. Natural History Publications (Borneo), Kota Kinabalu: 194-200.

Wangyal, J.T. and D.B. Gurung (2017). The current status of herpetofauna in Bhutan. In: Gurung, D.B. and O. Katel (eds.). An introduction to the biodiversity of Bhutan in the context of climate change and economic development. Centre for Rural Development Studies. College of Natural Resources, Lobesa, Punakha: 39-55.

Wangyal, J.T., D.S. Bower, Sherub, S. Tshewang, D. Wangdi et al. (2020). New Herpetofaunal Records from the Kingdom of Bhutan obtained through Citizen Science. Herpetological Review, 53 (4): 792-800.

Yang, D. and D. Rao (2008). Amphibia and Reptilia of Yunnan [in Chinese]. Yunnan Science and Technology Press, Kunming: 152pp.

Submitted: 27 January, Accepted: 15 March 2021 Section Editor: Nikolay A. Poyarkov

J.T. Wangyal ${ }^{1,2}$ S. Phuntsho ${ }^{3} \&$ K. Wangchuk ${ }^{3}$

${ }^{1}$ University of New England, Armidale NSW 2351, Australia; E-mail: jigmewangyal@gmail.com

${ }^{2}$ Jigme Khesar Strict Nature Reserve, Haa 15001, Bhutan

${ }^{3}$ Zhemgang Forest Division, Zhemgang 34001, Bhutan 